\title{
MRI comparative study of levator ani muscle changes in nulliparous and multiparous females
}

\author{
Heba Azzam ${ }^{1 *}$ D, Manal Halim¹, Hany El-Assaly ${ }^{1}$ and Aya Heiba ${ }^{2}$
}

\begin{abstract}
Background: Pelvic floor dysfunction is known to be among the principal factors influencing public health, regarding frequency, cost and effect on women's quality of life. Radiographic assessment of the pelvic floor function and anatomy plays a vital role in the recognition of pelvic floor defects. The aim of this study is to detect the postpartum-related levator ani muscle changes thus defining the relationship between the vaginal deliveries and the etiology of pelvic floor dysfunction in order to provide guidelines to decrease the incidence of pelvic floor injuries during parturition and guide the treatment plan.

Results: There was a significant difference in the puborectalis muscle thickness between the case and control groups in the right puborectalis $(P$ value $\leq 0.001)$ and in the left puborectalis ( $P$ value $(\leq 0.001)$ as well as significant midpoint thickness $(P$ value $=0.03$ ) with $46.2 \%$ puborectalis muscle injury in the case group compared with none in the control group.

Conclusion: Pelvic floor MRI is highly recommended as it is a contrast-free modality that allows for both anatomical and functional analysis. Its incorporation in the routine postpartum assessment will allow early detection of abnormalities even in asymptomatic cases thus ensuring proper management and preventing the development of pelvic floor dysfunction predisposed to by repeated vaginal deliveries.
\end{abstract}

Keywords: Postpartum, Pelvic floor dysfunction, Static, Dynamic, Magnetic resonance imaging

\section{Background}

Pelvic floor dysfunction is known to be among the principal factors influencing public health, regarding frequency, cost, and effect on women's quality of life [1].

Vaginal delivery is considered to be the most eminent predisposing factor for prolapse as a result of levator muscle insult, which has serious consequences on pelvic organ support and is strongly associated with pelvic organ prolapse [2].

During vaginal childbirth, the levator ani muscle is subjected to extensive deformation with consequent stretch-related injuries including tearing of the muscle as well as atrophy. The puborectalis muscle is required to be stretched during delivery to more than three times its original length. This stretching is over twice what the

\footnotetext{
* Correspondence: heba.m.azzam@gmail.com

${ }^{1}$ Diagnostic and Interventional Radiology, Cairo University, Maadi, Cairo,

Egypt

Full list of author information is available at the end of the article
}

striated muscle can endure without injury in a nonpregnant female [3]. Therefore, levator ani muscle (LAM) injuries occur in 13-36\% of women following vaginal childbirth [4].

The levator ani muscle complex represents the main support for the pelvic organs and assists to preserve their continence. The levator ani muscles are concealed in the pelvis making their assessment clinically very difficult [5].

In order to diagnose levator muscle injury, the available imaging modalities are ultrasound and magnetic resonance imaging (MRI). Three-dimensional (3D) ultrasound has the advantage of being cheap and accessible facilitating its application during pregnancy and the puerperium to assess the levator ani muscle. Yet limited wave depth is a disadvantage that might fail to detect potential injuries as well as morphological changes following delivery [6]. 
Magnetic resonance imaging (MRI) has been utilized to evaluate pelvic floor disorders from the mid-1980s by imaging the levator ani complex due to its multiplanar capability and superior soft-tissue contrast as well as high temporal resolution. Static images are used to assess the morphological features of the levator ani complex while dynamic images during straining and contraction are utilized to assess the functional changes [5].

\section{Methods}

This study is a case-control study (cases and controls are of matching sex and age), during the period from October 2017 to April 2018.

This study was approved by the research ethics committee of the radiology department in our institute. All patients included in this study gave written informed consent to participate in the research.

\section{Patients}

It included 52 female patients. The case group, 34 females with previous vaginal deliveries; the control group, 26 females with no previous history of vaginal delivery. Both were subjected to static and dynamic noncontrast MRI scanning.

\section{Inclusion criteria for the patient group}

- Adult female patients, age starting from 20 years and below 60 years.

- Having a previous history of single or multiple vaginal deliveries.

- Having different symptoms of pelvic floor weakness and dysfunction, ranging from urinary incontinence up to descending perineum syndrome.

\section{Inclusion criteria for the control group}

- Adult female patients, age starting from 20 years and below 60 years.

- Not complaining of any symptom of pelvic floor weakness or dysfunction.

- No previous history of vaginal delivery.

\section{Exclusion criteria}

- Previous pelvic floor surgeries.

- Nulliparous women with pelvic floor dysfunction related symptoms.

\section{MR imaging}

MRI was performed for the pelvic floor using 1.5 Tesla magnet scanners by two devices (Intera and Achieva, Philips medical system). All patients were examined in the supine position using a torso body coil. Total study time ranged from 30 to $45 \mathrm{~min}$. No sedation was used.

\section{Patient preparations}

- All patients underwent rectal enema the night before the MRI examination. No fasting preexamination was required. Patients were asked not to void $2 \mathrm{~h}$ before the examination. Explanation of the technique and training of the patients was done prior to the examination to ensure the patient understands how to preform Valsalva maneuver properly. The rectum was opacified with 120-180 $\mathrm{ml}$ of ultrasonography gel (Aquasonic; Parker Laboratories, Fairfield, NJ) in patients with anal incontinence and increased to $300 \mathrm{ml}$ in patients of obstructed defecation syndrome. Pads were placed underneath the patients to protect the coils and ensuring patient comfort. Elevating patients' legs by a pillow was done in patients with obstructed defecation symptoms to facilitate evacuation. A doctor was attending all the examinations and accompanying the patients during the dynamic scan to make sure they are compliant and to explain what they are expected to do at each phase of the examination.

\section{MRI imaging protocol}

A) Static images:

- T2WIs turbo spin-echo sequences in three planes; axial, coronal and sagittal. [repetition time ms/echo time ms (TR/TE) 5000/132, field of view (FOV) 240-260 mm, slice thickness 2-4 mm, gap 0-0.5 $\mathrm{mm}$, number of signals acquired 2, flip angle 90 , matrix $512 \times 512$, acquisition time $3.12 \mathrm{~min}$ for each sequence].

- T2WIs fast balanced images (BFFE) (9.0/4.0, field of view $220 \mathrm{~mm}$, section of thickness $3 \mathrm{~mm}$, number of signals acquired 8 , flip angle 45 , matrix $512 \times 512$, acquisition time $2.12 \mathrm{~min}$ ) of the anal sphincter complex with the image orientation parallel and perpendicular to the plane of the anal canal, Axial T2WIs.

B) Dynamic images:

- Balanced fast echo (BFFE) sequence images (TR/ TE 5.0/1.6 ms, FOV $300 \mathrm{~mm}$, slice thickness 5-7 $\mathrm{mm}$, gap $0.0-0.7 \mathrm{~mm}$ ) in three planes: axial, coronal, and sagittal. 
- Sagittal plane: Acquisition of five sections during 5 phases: At rest, contraction of pelvic floor, mild, moderate, and maximum straining.

- Coronal and axial planes: Acquisition of three sections during 3 phases: At rest, moderate, and repeated maximum straining to ensure maximal Valsalva maneuver.

- Evacuation phase: 5 dynamic scans were acquired in the sagittal plane with slice thickness $3 \mathrm{~mm}$, gap 0 $\mathrm{mm}$. The evacuation sequence was considered adequate when the injected gel is seen passing through the anal canal lumen.

C) Image post-processing and analysis:

Qualitative and quantitative analysis of the MR images was done as a double-blind analysis by two radiologists one with 5 years of experience and the other with 9 years of experience. The inter-observer variability was 0.6.

A basic understanding of pelvic floor anatomy is essential for adequate anatomic and functional evaluation of the pelvic floor on MR imaging. For purposes of clinical evaluation, the female pelvis is classically divided into 3 compartments: the anterior compartment containing the bladder and urethra; the middle compartment containing the uterus, cervix, and vagina; and the posterior compartment containing the rectum and anal canal [7].

These compartments are closely inter-related, and usually patients present with multi-compartmental dysfunction. The compartments of the pelvic floor are supported by a complex network of fascia, ligaments, and pelvic floor muscles that form 3 layers of support the endopelvic fascia (superior), the pelvic diaphragm which is also called levator ani complex (middle), and the perineal membrane or urogenital diaphragm (inferior). The fascia and ligaments provide passive support, while the pelvic diaphragm muscles provide the underlying tone and can be recruited for active support [8].

I. Analysis of static images:

- Endopelvic fascial defect: which wraps the pelvic organs supporting them "but it is normally too thin to be recognized at MR imaging except for its condensations (the cardinal, uterosacral, and urethral ligaments) Level I fascial defect: it is caused by detachment of the uterosacral ligament with consequent posterior sagging of the vagina bilaterally giving the "chevron sign". Level II fascial defect: it is caused by loss of the vaginal supporting fascia from the lateral pelvic wall leading to sagging of the posterior urinary bladder wall and loss of vaginal normal configuration that is known as "Saddle Bags sign" Level III fascial defect: it is caused by bilateral sagging of the fat in the pre-vesical space against the detached lower third of the anterior vaginal wall from the arcus tendineus fascia pelvis it is recognized as "Drooping Mustache" [8, 9].

- Vaginal configuration: normally it is butterfly or $\mathrm{H}$ shaped.

- Urethral supporting ligaments: they are assessed for asymmetry, any disruption or discontinuity, they are divided into anterior ligaments which are the periurethral ligaments arise from the puborectalis muscle and course ventrally to the urethra, whereas the paraurethral ligaments arise from the lateral wall of the urethra to the periurethral ligaments, and the pubourethral ligaments a pair of fibromuscular ligaments close to the midline [10]. and dorsal ligaments which are suburethral ligament is seen dorsal to the urethra, runs posterior to it in the form of a suburethral sling, having a plane of cleavage between this ligament and the anterior vaginal wall [11].

- Puborectalis muscles: were assessed for muscle thickness and defects

- Iliococcygeus muscles: were assessed for muscle thickness, loss of the normal symmetric appearance of its muscle slings or defects.

- Anal sphincter: is assessed for structural change: which may be in the form of either tears/defect "discontinuity of the muscle ring" or scarring "low-signal-intensity deformation of the normal muscle pattern" and volume change: classified into Focal "Thinning or Thickening" or Diffuse "Atrophy" volume change [8, 9]. (Figs. $1 \mathrm{~d}$ and 2d, e).

\section{Analysis of dynamic images:}

A) The supportive measurements:

- H-line: it is the distance from the inferior symphysis pubis to the posterior ARJ, representing the anteroposterior width of the levator hiatus.

- M-line: the perpendicular distance from the PCL (pubococcegeal line) to the most distal aspect of the $\mathrm{H}$-line to evaluate levator plate activity. 

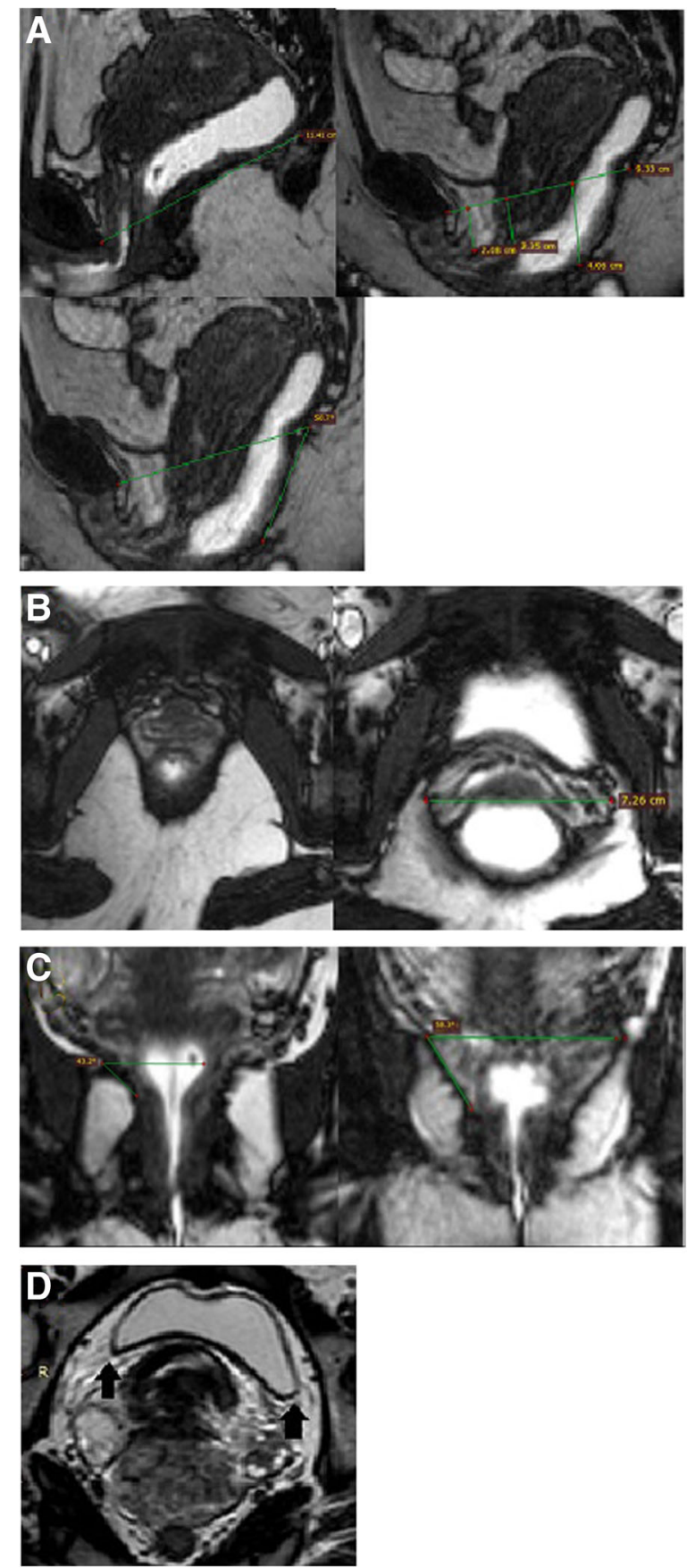

Fig. 1 Static and dynamic images: a sagittal, b axial, c coronal, static images: $\mathbf{d}$ axial. The sagittal images (a) showed the PCL in static images, the dynamic images revealed anterior, middle, and posterior compartmental pelvic organ descent below the PCL and increased levator plate angle. The axial images (b) showed the difference between the width of the levator hiatus in static and dynamic sequences. The coronal images (c) showed the difference between the iliococcygeal angle in the static and dynamic sequences. Axial static images (d) showed level II endopelvic fascial defect as evidenced by bi-posterolateral sagging of the posterior bladder wall being more evident on the left side (saddle bag sign)
- Levator plate angle (LPA): it is measured in the midsagittal dynamic plane at rest and on straining in relation to the PCL.

- The iliococcygeus angle: it is measured in the dynamic coronal plane at the level of the anal canal between the iliococcygeus muscle and the transverse plane of the pelvis "obtained by joining the point the iliococcygeus muscle originates from the obturator internus". It reflects the degree of movement and descent of the muscle.

- The levator hiatus width: it is measured in the axial dynamic plane between the medial aspect of the right and left levator ani muscle at the level of the lateral vaginal wall for any asymmetry or ballooning (Figs. $1 \mathrm{a}-\mathrm{c}$ and $2 \mathrm{a}-\mathrm{c}$ ).

B) Pathological structural abnormalities were assessed at the midsagittal plane at (maximum straining and evacuation phases) (Figs. 1a, 2a, and 3).

- Anterior compartment dysfunction: bladder neck and base "cystocele" descents.

- Middle compartment dysfunctions: uterine descent and vaginal vault descent "in cases of hysterectomy" below the PCL.

- Anorectal junction descent (ARJ)

- Rectocele

- Other abnormalities: the presence of abnormalities such as rectal intussusception, rectal prolapse, puborectalis dyskinesia, peritoneocele, sigmoidocele, and enteroceles.

\section{Statistical analysis:}

Results were tabled and statistically analyzed using SPSS vs. 15. Parametric data was expressed as minimum, maximum, mean and SD. Comparison between two groups was done using unpaired $t$ test $(t)$. Comparison between more than two groups was done using the one-way ANOVA test $(F)$.

Non parametric data was expressed as number and percentage. Comparison between two groups or more was done using chi-square $\left(X^{2}\right)$. Correlation between two parametric variables was done using Pearson's correlation $(r)$. Two-tailed $P$ value $>0.05$ was considered insignificant and $\leq 0.05$ was considered significant. 


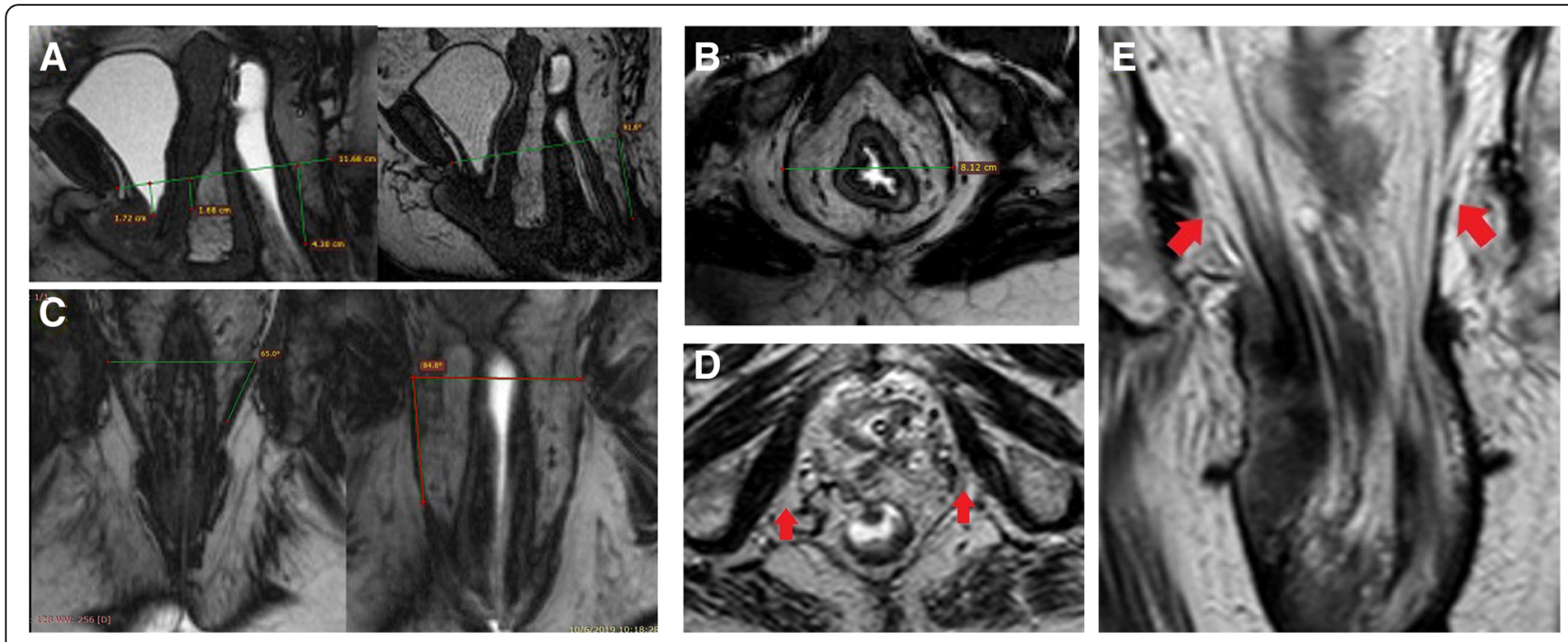

Fig. 2 Dynamic images: a sagittal, b axial, c coronal; static images: $\mathbf{d}$ axial and e coronal. The sagittal dynamic images revealed anterior, middle, and posterior compartmental organ descent below the PCL and increased levator plate angle at the midsagittal plane. The axial images (b) showed ballooning of the levator hiatus. The coronal images (c) showed the difference between the iliococcygeal angle in the static and dynamic sequences. Axial static images (d) showed bilateral torn puborectalis muscles. Coronal static images (e) showed extremely thinned out iliococcygeus muscles with discontinuity of its fibers on the right side on coronal images

\section{Results}

Fifty-two female patients were included in this study, their age ranged from 20 to 59 years, they were divided into two groups, case group; twenty-six females who underwent vaginal deliveries with mean age 41.1 years. Control group; twenty-six nullipara females of mean age 34.35 years.

Comparison of pelvic floor muscle thickness in both groups revealed significant affection of both right and left puborectalis muscles in the case group with $P$ value $(\leq 0.001)$. Also, the left iliococcygeus and puborectalis midpoint thickness were significantly affected in the case group with $P$ value ( 0.05 and 0.03 respectively). Yet the right iliococcygeus showed no significant difference (Table 1).

In the case group, $46.2 \%$ had puborectalis muscle injury:, ranging from partial thickness tears up to bilateral full thickness tear divided as follows: $11.5 \%$ right partial thickness tear,7.7\% right insertion detachment, 7.7\% bilateral partial thickness tear, 3.8\% right full thickness tear, 3.8\% left full thickness tear, 3.8\% bilateral full thickness tear, $3.8 \%$ right partial thickness tear as well as midpoint disruption, and 3.8\% midpoint disruption only. $88.5 \%$ of the case group showed no ilio-coccygeus tear, $3.9 \%$ left partial thickness tear, 3.9\% right partial thickness tear and 3.9\% left full thickness tear. As a conclusion, we can say that puborectalis muscles are affected more commonly than ilio-coccygeus muscles (Table 2).

Pelvic floor descent occurred with different grades in almost all gravida cases (34.6\% severe, $46.2 \%$ moderate and $19.2 \%$ mild). Hiatal enlargement beyond normal values occurred in $88.5 \%$ of the case group $(57.7 \%$ mild,
$26.9 \%$ moderate, and 3.9 severe) while $11.5 \%$ showed normal hiatal enlargement.

Among the studied cases, we found that $3.85 \%$ of cases have mono-compartment affection, 23\% bi-compartments affection, and 73\% has multi-compartmental affection; Accordingly, the majority of cases have multi-compartmental affection.

In the anterior compartment $73.1 \%$ of the case group had bladder neck descent and $50 \%$ had cystoceles divided into $30.8 \%$ mild, $15.4 \%$ moderate, and $3.8 \%$ severe grades. The middle compartment is affected in $92.3 \%$ of the cases having cervical descent "vaginal vault descent in hysterectomy cases $(53.8 \%$ mild, 34.6 moderate, and 3.9 severe). In the posterior compartment, $92.3 \%$ of cases had rectal prolapse and $73.1 \%$ had rectocele $(57.7 \%$ moderate and 15.4 mild) (Table 3).

The levator plate angle and the iliococcygeus angle were increased in $96.2 \%$ and $92.3 \%$ of the cases respectively. The endopelvic fascia was affected in $88.5 \%$, all levels were affected in $38.5 \%$, level III in $34.7 \%$, levels I and II in $11.5 \%$, and levels II and III in $3.8 \%$. As for urethral ligaments, they were affected in $26.9 \%$ right suburethral tear/ distortion in $3.8 \%$ and bilateral suburethral tear/distortion in $23.1 \% .7 .6 \%$ of cases had incontinence with equal prevalence of urinary incontinence only and both urinary incontinence and stool incontinence $3.8 \%$ each.

There was decreased muscle thickness with age as the right puborectalis showed a highly significant $P$ value of 0.004; the left puborectalis and puborectalis midpoint thickness showed significant $P$ values 0.01 and 0.03 respectively yet the right and left iliococcygeus muscles showed nonsignificant $P$ values of 0.45 and 0.16 respectively. 

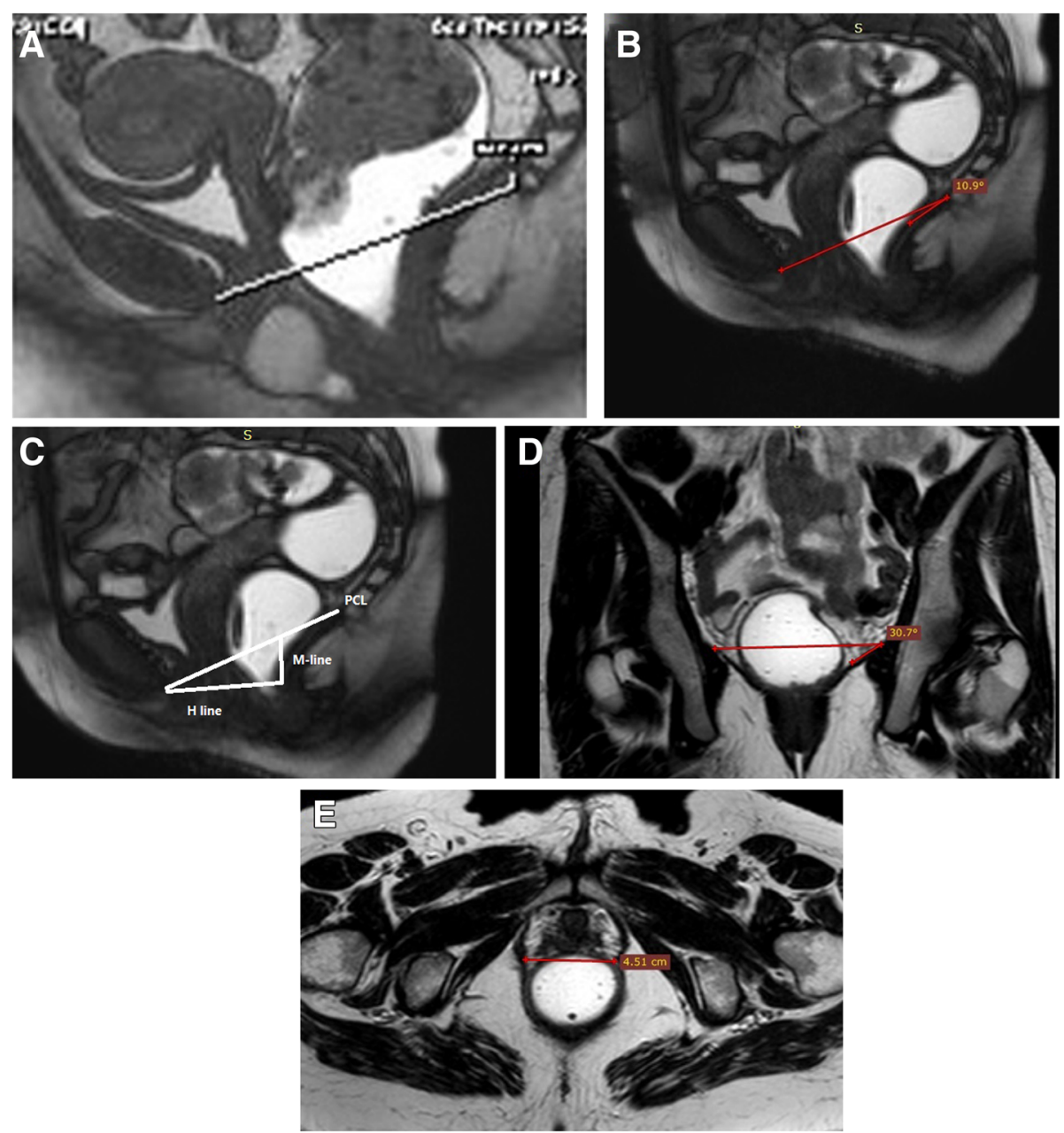

Fig. 3 Dynamic images ( $\mathbf{a}, \mathbf{b}$, and $\mathbf{c}$ ) sagittal, $\mathbf{d}$ coronal, and $\mathbf{e}$ axial images of a normal control patient. The sagittal dynamic images (a) revealed no abnormal anterior, middle, or posterior compartmental organ descent below the $\mathrm{PCL}$, $\mathbf{b}$ showed normal levator plate angle, and $\mathbf{c}$ revealed normal $\mathrm{H}$ and $\mathrm{M}$ lines. The coronal dynamic images (d) revealed normal iliococcygeal angle. The axial dynamic images (e) revealed normal width of the hiatus

There was also decreased muscle thickness with increased number of vaginal delivery; the right and left puborectalis muscles thickness in multi-gravida are significantly affected, with highly significant $P$ values 0.014 and 0.01 , respectively, yet the puborectalis midpoint and both iliococcygeus muscles showed nonsignificant affection.

\section{Discussion}

Vaginal delivery is considered to be the most eminent predisposing factor for prolapse as a result of levator muscle insult, which has serious consequences on pelvic organ support and is strongly associated with pelvic organ prolapse [2].

Magnetic resonance imaging (MRI) of the pelvic floor has become an increasingly utilized method for pelvic floor weakness assessment and pelvic organ prolapse. It allows assessment of all the compartments at rest and strain within a single examination. In addition, MRI allows assessment of the muscular and ligamentous anatomy of the pelvic floor as well as potential other incidental findings that may contribute to the symptoms. Moreover, MRI is less invasive, does not entail any ionizing radiation, and is less dependent on operators [12].

In the dynamic scans, we studied changes in all three compartments of the pelvic floor as pelvic floor dysfunction is almost always multi-compartmental even if the presentation was unicompartmental.

Among the studied cases, we found that $3.85 \%$ of cases have mono-compartment affection, 23\% bi-compartments affection, and $73 \%$ had multi-compartmental affection; accordingly, the majority of cases have multi-compartmental affection.

As for the anterior compartment, $73.1 \%$ of the case group had bladder neck descent and 50\% had cystoceles, 
Table 1 Comparison between case and control groups muscle thickness

\begin{tabular}{|c|c|c|c|c|}
\hline & Case $(n=26)$ & Control $(n=26)$ & $t$ & $P$ \\
\hline Rt ilio-coccygeus (mm) & & & 0.83 & 0.4 \\
\hline Min.-max. & $2-6.2$ & $3-6.8$ & & \\
\hline Mean \pm SD & $4.02 \pm 1.15$ & $4.3 \pm 1.03$ & & \\
\hline Lt ilio-coccygeus (mm) & & & 1.98 & 0.054 \\
\hline Min.-max. & $1.4-5.1$ & $2.6-6.4$ & & \\
\hline Mean \pm SD & $3.69 \pm 1.1$ & $4.3 \pm 1.03$ & & \\
\hline Rt puborectalis (mm) & & & 4.53 & $\leq .001$ \\
\hline Min.-max. & $1.7-12$ & $7.2-12$ & & \\
\hline Mean \pm SD & $6.67 \pm 2.34$ & $9.1 \pm 1.38$ & & \\
\hline Lt puborectalis (mm) & & & -4.95 & $\leq .001$ \\
\hline Min.-max. & $1.7-11$ & $7.8-15$ & & \\
\hline Mean \pm SD & $6.7 \pm 2.25$ & $9.5 \pm 1.8$ & & \\
\hline Midpoint puborectalis (mm) & & & -2.22 & 0.03 \\
\hline Min.-max. & $2.6-11$ & $5.3-9.5$ & & \\
\hline Mean \pm SD & $5.9 \pm 2.1$ & $6.9 \pm 0.99$ & & \\
\hline
\end{tabular}

while in the middle compartment, $92.3 \%$ of the cases had cervical descent "vaginal vault" descent in hysterectomy. In the posterior compartment, $92.3 \%$ of cases had rectal prolapse and $73.1 \%$ had rectocele.

The above findings are in concordance with Bitti et al. [13] and Law et al. [10] who reported that female patients presenting with symptoms of unicompartmental affection often have generalized damage of

Table 2 Pelvic floor muscles abnormalities in case group

\begin{tabular}{lll}
\hline & $N$ & $\%$ \\
\hline llio-coccygeus defect & 23 & 88.5 \\
No tear & 1 & 3.9 \\
Rt partial tear & 1 & 3.9 \\
Lt partial tear & 0 & 0.00 \\
Rt full tear & 1 & 3.9 \\
Lt full tear & & \\
Puborectalis defect: & 14 & 53.8 \\
No tear & 2 & 7.7 \\
Rt insertion detachment & 0 & 0.0 \\
Lt insertion detachment & 0 & 0.0 \\
Bilateral insertion detachment & 3 & 11.5 \\
Rt partial tear & 2 & 7.7 \\
Bilateral partial tear & 1 & 3.8 \\
Rt full tear & 1 & 3.8 \\
Lt full tear & 1 & 3.8 \\
Bilateral full tear & 1 & 3.8 \\
Distorted midpoint & 1 & 3.8 \\
Rt partial and distorted midpoint & &
\end{tabular}

their pelvic floor as a whole with increased incidence of recurrence following repair of the symptomatic compartment only.

This is also in agreement with Woodfield et al. [14] who reported the superiority of MRI having the capability to assess the pelvic floor support structures as well as

Table 3 Compartmental abnormalities in case group

\begin{tabular}{lll}
\hline & N & $\%$ \\
\hline BN descent "anterior compartment": & & \\
- ve & 7 & 26.9 \\
+ ve & 19 & 73.1 \\
Cystocele "anterior compartment": & & \\
Normal & 13 & 50 \\
Mild & 8 & 30.8 \\
Moderate & 4 & 15.4 \\
Severe & 1 & 3.8 \\
Cervix or vaginal vault "middle compartment": & \\
Normal & 2 & 7.7 \\
Mild & 14 & 53.8 \\
Moderate & 9 & 34.6 \\
Severe & 1 & 3.9 \\
ANRJ descent "posterior compartment": & \\
- ve & 2 & 7.7 \\
+ ve & 24 & 92.3 \\
Rectocele "posterior compartment": & & 26.9 \\
Normal & 7 & 15.4 \\
Small outpouching & 4 & \\
Moderate & 15 & \\
\hline
\end{tabular}


simultaneously scanning all pelvic compartments in order to detect pelvic organ prolapse in any compartment as usually more than one compartment is affected.

In this study, there was a significant difference between case and control groups in pelvic floor muscle thickness with $P$ value $\leq 0.001$ for right and left puborectalis muscles and $P$ value 0.05 and 0.03 for left ilicoccygeus and puborectalis midpoint thickness, respectively, with $46.2 \%$ of the case group having puborectalis muscle injury and $11.5 \%$ having iliococcygeus muscle injury. The correlation between vaginal delivery and muscle thickness revealed a significant difference in the right and left puborectalis muscle thickness in multi-gravida with $P$ value $=0.014$ and 0.01 .

This agrees with Leijonhufvud et al. [15] who reported increased rates of surgeries for stress urinary incontinence and pelvic organ prolapse surgery with increased number of vaginal deliveries.

Also agreeing with Bitti et al. [13] who stated that the puborectalis muscle is often injured during vaginal delivery, the injuries can be in the form of tear, thinning, bowing, and atrophy following pudendal nerve affection.

Similarly, Naganawa et al. [16] stated that there is a directly proportionate relation between the number of vaginal deliveries and downward displacement of the rectum; there were significant differences in the distance from the rectum descent to PCL between the nulliparous and multipara groups $(p<0.01)$.

Those results are coinciding with those stated by Yan et al. [17] who studied 80 women 45-60 days postpartum showing a prevalence of puborectalis injuries in $13.75 \%$. They also emphasized the importance of postpartum MRI examination to rule out associated iliococcygeus muscle injuries or thinning that can be missed by ultrasound examination. These results also agreed with Alt et al. [18] detecting numerous superficial and deep pelvic morphological changes between nulliparous and primiparous female $(P<0.001)$.

DeLancey et al. [19] disagree with these results as they studied the integrity and bulk of puborectalis muscle by MRI following vaginal delivery and stated that it was visible in its expected location with no evidence of muscle avulsion from its pubic attachment.

In this study, we detected that puborectalis muscle thickness decrease with age with $p$ values $0.004,0.01$ and 0.03 for the right puborectalis, the left puborectalis and puborectalis mid point thickness respectively while iliococcygeus muscles showed no significant difference.

This agrees with Alperin et al. [20] who discovered that the thickness of all pelvic floor muscles was siginificantly decreased with aging $(P<0.05)$.

Also, Rahmanou et al. [21] stated that there is a noteworthy correlation found between the increased age of the primigravida mother and the risk of pelvic floor injury with evidence of at least one form of major pelvic floor trauma $(P=0.003)$ as well as levator avulsion in (18.7\%), micro-trauma in (12.8\%), and obstetric anal sphincter injuries in (24.4\%).

This was consistent with the previous researches done by Bozkurt et al. [22] who stated that the incidence of pelvic floor dysfunction rises markedly with age nearly $10 \%$ of women with age range 20 to 39 years, in comparison with $50 \%$ of females aged $\geq 80$ years suffer from at least one pelvic floor dysfunction disorders, with higher prevalence in multiparous females compared with nulliparous females, thus emphasizing the role of obstetric trauma.

In this study, the relation between pelvic floor descent and both PR and IL muscle thickness without tears as well as muscle defects was insignificant with $P$ value $\geq$ 0.05; that was agreeing with Dietz HP et al. [23] whose study was designed to quantify the role of a direct childbirth trauma to the insertion of the puborectalis muscle, on the inferior pubic ramus. Such trauma is common and clearly linked to vaginal delivery; their results stated pelvic organ prolapse was seen in 150/181 (83\%) women with puborectalis defects and in 265/600 (44\%) women without puborectalis defects $(P<0.0001)$.

\section{Conclusion}

MRI is the modality of choice for identifying and grading of pelvic floor dysfunction as well as the underlying anatomical defects and it should be routinely performed postpartum for screening of pelvic floor injuries and hence allowing early detection of abnormalities with prompt treatment thus preventing the development of PFD predisposed to by vaginal deliveries.

\section{Abbreviations \\ 3D: Three-dimensional; IL: lliococcygeus; LAM: Levator ani muscle; LPA: Levator plate angle; MRI: Magnetic resonance imaging; PCL: Pubo- coccygeal line; PFD: Pelvic floor dysfunction; PR: Puborectalis}

\section{Acknowledgements}

Not applicable.

\section{Authors' contributions}

All authors have read and approved the manuscript. $\mathrm{HA}, \mathrm{MH}, \mathrm{HE}$, and $\mathrm{AH}$ contributed equally to this work. $\mathrm{HA}$ and $\mathrm{MH}$ designed research. $\mathrm{HA}$ and $\mathrm{AH}$ performed research. $\mathrm{HE}$ and $\mathrm{MH}$ analyzed data. HA and HE Wrote the paper.

\section{Funding}

Not applicable (no funding received for this study).

\section{Availability of data and materials}

All the datasets used and analyzed during this study are available with the corresponding author on reasonable request.

\section{Ethics approval and consent to participate}

This study was approved by the research ethics committee of the Radiology department of the Faculty of Medicine Cairo University on 5/7/2017,

Reference number of approval: 914-2017.

All patients included in this study gave written informed consent to participate in the research. If the patient was less than 16 years old, or 
unconscious at the time of study, written informed consent was given by their parent or legal guardian.

\section{Consent for publication}

All patients included in this study gave written informed consent to publish the data contained in this study. If the patient was less than 16 years old, or unconscious at the time of study, written informed consent was given by their parent or legal guardian.

\section{Competing interests}

The authors declare that they have no competing interests.

\section{Author details}

'Diagnostic and Interventional Radiology, Cairo University, Maadi, Cairo, Egypt. ${ }^{2}$ Diagnostic Radiology, Police Hospital, Cairo, Egypt.

Received: 5 September 2019 Accepted: 10 October 2019

Published online: 26 November 2019

\section{References}

1. Torrisi G, Minini G, Bernasconi F, Perrone A, Trezza G, Guardabasso V, Ettore $G$ (2012) A prospective study of pelvic floor dysfunctions related to delivery. Eur J Obstet Gynecol Reprod Biol 160:110-115

2. Dietz HP, Moegni F, Shek KL (2012) Diagnosis of levator avulsion injury: a comparison of three methods. Ultrasound Obstet Gynecol 40:693-698

3. Krofta L, Havelková L, Urbánková I, Krčmár M, Hynčík L, Feyereisl J (2017) Finite element model focused on stress distribution in the levator ani muscle during vaginal delivery. Int Urogynecol J 28(2):275-284

4. Schwertner-Tiepelmann N, Thakar R, Sultan AH, Tunn R (2012) Obstetric levator ani muscle injuries: current status. Ultrasound Obstet Gynecol 39: 372-383

5. Cai XR, Qiu L, Wu HJ, Liu SR (2013) Assessment of levator ani morphology and function in asymptomatic nulliparous women via static and dynamic magnetic resonance imaging. Int J Gynecol Obstet 121:233-239

6. Dietz HP, Shek C, Clarke B (2005) Biometry of the pubovisceral muscle and levator hiatus by three-dimensional pelvic floor ultrasound. Ultrasound Obstet Gynecol 25:580-585

7. Garcia del Salto L, de Miguel Criado J, Aguilera del Hoyo LF, Gutierrez Velasco L, Fraga Rivas P, Manzano Paradela M, Diez Perez de las Vacas MI, Marco Sanz AG, Fraile Moreno E (2014) MR Imaging-based assessment of the female pelvic floor. Radiographics 34(5):1417-1439

8. Khatri G, de Leon AD, Lockhart ME (2017) MR imaging of the pelvic floor. Magn Reson Imaging Clin N Am 25(3):457-480

9. Piloni VL, Muggia F (2016) Combined three-dimensional Transperineal ultrasonography (3-D TPUS) and magnetic resonance imaging (MRI) after vaginal delivery. In: Riva D, Minini G (eds) Childbirth-related pelvic floor dysfunction. Springer, Cham

10. Law YM, Fielding JR (2008) MRI of Pelvic Floor Dysfunction: Review. Am J Roentgenol

11. El Sayed R, Morsy M, El Mashed S, Abdel-Azim M (2007) Anatomy of the urethral supporting ligaments defined by dissection, Histology, and MRI of Female Cadavers and MRI of Healthy Nulliparous Women. AJR Am J Roentgenol 189(5):1145-1157

12. Rosenkrantz AB, Lewis MT, Yalamanchili S, Lim RP, Wong S, Bennett GL (2014) Prevalence of pelvic organ prolapse detected at dynamic MRI in women without history of pelvic floor dysfunction: comparison of two reference lines. Clin Radiol 69(2):e71-e77

13. Bitti GT, Argiolas GM, Ballicu N, Caddeo E, Cecconi M, Demurtas G, Matta G, Peltz MT, Secci S, Siotto P (2014) Pelvic floor failure: MR imaging evaluation of anatomic and functional abnormalities. Radiographics 34:429-448

14. Woodfield CA, Krishnamoorthy S, Hampton BS (2010) Imaging pelvic floor disorders: trend toward comprehensive MRI. Am J Roentgenol 194(6):1640-1649

15. Leijonhufvud A, Lundholm C, Cnattingius S (2011) Risks of Stress Urinary Incontinence and Pelvic Organ Prolapse Surgery in Relation to Mode of Childbirth. Am J Obstet Gyneco 204(1):70.e1-70.e7

16. Naganawa S, Maeda E, Hagiwara A, Amemiya S, Gonoi W, Hanaoka S, Yoshikawa T, Ohtomo K (2017) Vaginal delivery-related changes in the pelvic organ position and vaginal cross-sectional area in the general population. Clin Imaging 50:86-90
17. Yan Y, Dou C, Wang X, Xi Y, Hu B, Ma L, Ying T (2017) Combination of tomographic ultrasound imaging and three-dimensional magnetic resonance imaging-based model to diagnose postpartum Levator avulsion. Sci Rep 7(1):1-9

18. Alt CD, Hampel F, Radtke JP, Hallscheidt P, Schlehe B, Sohn C, Brocker K (2017) Early postpartum pelvic floor changes in Primiparous women after vaginal delivery using 3T MRI. Neurourol Urodyn 36(8):1-10

19. DeLancey J, Sørensen HC, Lewicky-Gaupp C, Smith TM (2012) Comparison of the Puborectal muscle on MRI in women with POP and Levator Ani defects with those with Normal support and no defect. Int Urogynecol J 23(1):73-77

20. Alperin M, Cook M, Tuttle L, Esparza M, Lieber R (2016) Impact of vaginal parity and aging on the architectural design of pelvic floor muscles. Am J Obstet Gynecol 215(3):312.e1-312.e9

21. Rahmanou P, Caudwell-Hall J, Kamisan Atan I, Dietz HP (2016) The association between maternal age at first delivery and risk of obstetric trauma. Am J Obstet Gynecol 215(4):451.e1-451.e7

22. Bozkurt M, Yumru AE, Şahin L (2014) Pelvic floor dysfunction, and effects of pregnancy and mode of delivery on pelvic floor. Taiwan J Obstet Gynecol 53(4):452-458

23. Dietz HP, Simpson JM (2008) Levator trauma is associated with pelvic organ prolapse. BJOG 115:979-984

\section{Publisher's Note}

Springer Nature remains neutral with regard to jurisdictional claims in published maps and institutional affiliations.

\section{Submit your manuscript to a SpringerOpen ${ }^{\circ}$ journal and benefit from:}

- Convenient online submission

- Rigorous peer review

- Open access: articles freely available online

- High visibility within the field

- Retaining the copyright to your article

Submit your next manuscript at $>$ springeropen.com 